\title{
A mass and energy balance stage model for cyclic distillation
}

Rasmussen, Jess Bjørn; Mansouri, Seyed Soheil; Zhang, Xiangping; Abildskov, Jens; Huusom, Jakob Kjøbsted

Published in:

AIChE Journal

Link to article, DOI:

10.1002/aic.16259

Publication date:

2020

Document Version

Peer reviewed version

Link back to DTU Orbit

Citation (APA):

Rasmussen, J. B., Mansouri, S. S., Zhang, X., Abildskov, J., \& Huusom, J. K. (2020). A mass and energy balance stage model for cyclic distillation. AIChE Journal, 66(8), [e16259]. https://doi.org/10.1002/aic.16259

\section{General rights}

Copyright and moral rights for the publications made accessible in the public portal are retained by the authors and/or other copyright owners and it is a condition of accessing publications that users recognise and abide by the legal requirements associated with these rights.

- Users may download and print one copy of any publication from the public portal for the purpose of private study or research.

- You may not further distribute the material or use it for any profit-making activity or commercial gain

- You may freely distribute the URL identifying the publication in the public portal

If you believe that this document breaches copyright please contact us providing details, and we will remove access to the work immediately and investigate your claim 


\section{A mass and energy balance stage model for cyclic}

\section{distillation}

Jess Bjørn Rasmussen ${ }^{1,2} \quad$ Seyed Soheil Mansouri ${ }^{1} \quad$ |

\section{Xiangping Zhang ${ }^{2} \quad$ Jens Abildskov ${ }^{1}$ | Jakob Kjøbsted}

Huusom ${ }^{1}$

1

${ }_{1}^{1}$ PROSYS, Department of Chemical and Biochemical Engineering, Technical University of Denmark, Søltofts Plads, Building 229,

2800 Kgs. Lyngby, Denmark

${ }^{2}$ ILC, Institute of Process Engineering, Chinese Academy of Sciences, No.1 Zhongguancun North 2nd Street, Haidan District, Beijing 100190, P.R. China

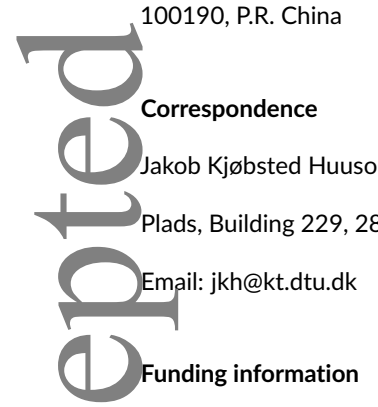

The authors received no specific funding for this work.

(

\section{Abstract}

Cyclic distillation is an emerging process intensification technology, which can improve the separation efficiency

compared to conventional distillation. Since most current models only account for the mass transfer, there is a lack

This article has been accepted for publication and undergone full peer review but has not been through the copyediting, typesetting, pagination and proofreading process, which may lead to differences between this version and the Version of Record. Please cite this article as doi: 10.1002/aic. 16259

(C) 2020 American Institute of Chemical Engineers (AIChE)

Received: Jan 02, 2020; Revised: Mar 28, 2020; Accepted: May 04, 2020 
of a stage model for cyclic distillation processes, which includes considerations of both mass and energy transfer.

Such a model is presented in this paper and using this model selected case studies, describing binary and multiple component systems with both ideal and non-ideal liquid phases, are investigated. The presented stage model allows for the modelling of both mass and energy transfer for a cyclic distillation process and allows for multiple feed locations as well as side draws. With the energy balances included the dynamic vapour flow rate can be described. This was shown to have a significant effect on the separation, especially for cases where the change in the vapour flow over the column height was high.

KEYWORDS

- Cyclic distillation, Process intensification, Distillation modelling, Periodic cycled separation

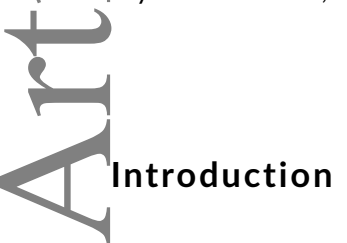

Distillation is a common fluid separation process in chemical and biochemical industry. It is often an expensive process, both in capital and operational cost due to low tray efficiencies and high energy requirements. In 2016 distillation processes alone accounted for approximately $8 \%$ of the total energy consumption in the U.S. ${ }^{1}$. Different process intensifications have been proposed in order to lower the cost and improve the separation efficiency of distillation processes ${ }^{2,3,4}$. One of these process intensifications is called cyclic distillation, sometimes also referred to as periodic distillation or controlled/periodic cycling of distillation processes.

It has been shown that there are key benefits in operating a distillation process with this periodic cycling, instead of the conventional way with continuous counter-current liquid and vapour flows. For example it could lead to either higher capacity ${ }^{5}$, better degree of separation ${ }^{6}$ or reduced energy requirements ${ }^{7}$ dependent on the process, column and stage design.

\section{| Development in cyclic distillation technology}

In 1936 Lewis investigated the tray efficiency in a distillation column for three different tray concepts assuming plug flow in the liquid phase ${ }^{8}$ :

This article is protected by copyright. All rights reserved. 
- Case I: Inlet vapour is completely mixed.

- Case II: Inlet vapour is not mixed and liquid moves across the tray in the same direction on all trays.

- Case III: Inlet vapour is not mixed and liquid moves counter-currently on the trays.

The first Lewis case describes a tray immediately above the reboiler (or the bottom tray in a absorption or stripper column), where the vapour has a uniform composition. The third Lewis case describes a tray in a conventional distillation column and it was later shown that a tray operated with periodic cycling is analogous to Lewis case II 9 Lewis calculated the tray efficiencies for different scenarios. When the point efficiency, $E_{\text {point }}$, and the ratio of the equilibrium and operational slopes were equal to one, he found that with a tray efficiency for the third case equal to $E_{\text {tray }} / E_{\text {point }}=1.5$, the tray efficiency for the second Lewis case would be $E_{\text {tray }} / E_{\text {point }}=2.0$, with the efficiency for case equal to $E_{\text {tray }} / E_{\text {point }}=1.72^{8}$. I.e. according to Lewis, a tray in a conventional distillation column has the lowest tray efficiency, and a tray similar to a tray in a cyclic distillation column has the highest tray efficiency of the three cases he investigated. With higher tray efficiencies in cyclic distillation the degree of separation is significantly improved compared to conventional distillation. This means a cyclic distillation column could be an improvement in terms of higher capacity, lower energy requirements, better separation performance and/or smaller columns with the same degree of separation.

In the early 1960's controlled cycling of a distillation process was proposed by Cannon et al. 5,10,11. They were the first to realise the benefits of cyclic distillation and that the second Lewis case tray could be realised with cyclic peration. In 1967 early pilot-scale experiments were conducted by Schrodt et al. ${ }^{12}$. For these pilot-scale experiments they used ordinary sieve trays. While they reported a high degree of separation as expected, they also noticed issues with non-uniform liquid draining for large columns (more than 12 trays). The problem they encountered with the draining was that some of the trays would drain completely before other trays. This meant back-mixing of the liquid holdups could not be avoided.

Since the early 1960's cyclic distillation have been extensively studied in lab-scale, pilot-scale and with simple modelling 12,13,14,15,16. Different tray design and operations have been proposed, including step-wise draining, pressure manifolds and trays with inclined surfaces ${ }^{17,18,19}$. These tray designs were intended to solve the issue with 
non-uniform draining first reported by Schrodt et al. ${ }^{12}$. However, none of the proposed designs solved the problem sufficiently. Between 1990 and 2010 the number of publications on cyclic distillation is scarce. It was not until a new viable tray design was proposed in 2011 by Maleta et al. ${ }^{20}$ that the issues with non-uniform draining were solved for any number of stages. With this new tray design that allows full-scale distillation columns being operated in cyclic mode together with an increase in computational power, the interest in cyclic distillation was rekindled. Since 2011 new papers have been published, focusing on the modelling, design and control of cyclic distillation processes as well as on experimental work ${ }^{7,21,22,23,24,25,26}$. Due to the increase in computational power the complexity of the models has also increased. The first mass balance based models from the 20th century described stripping processes with assumptions of linear equilibrium, binary mixtures and saturated liquid feed ${ }^{7,13,14}$. The newer models are capable of simulating full distillation columns with non-linear equilibrium and multi-component mixtures. Despite the increased complexity in the models, the current state-of-the-art model by Pătruţ et al. is still only mass balance based and with assumption of saturated liquid feed ${ }^{6}$. Pătruţ et al. also included a term for a stage dependent vapour flow rate based on the heat of vaporisation on each stage, but not on the energy transfer. Nielsen et al. proposed a driving force based design algorithm for cyclic distillation including non-saturated liquid feed ${ }^{24}$. The first attempt to set up a mass and energy balance model was presented by Andersen et al. ${ }^{21}$. The model by Andersen et al. includes the energy balance for all stages, but only with a single feed and no additional energy terms. The purpose of their model was o describe the integrated column design, based on the method by Nielsen et al. ${ }^{24}$, and control configuration. While considerations of the energy transfer on each stage is included in the model, it does not give a general description of the process and while the time dependent vapour flow rate is mentioned, it is not explicitly presented.

For pilot scale or industrial applications there are currently two draining methods available: A simultaneous draining, where all trays are drained to the tray below at the same time, and a sequential draining ${ }^{27,28}$, where the stages are drained and filled one-by-one starting from the bottom and to the top of the column. The simultaneous draining method is the most studied method and can be achieved with the Maleta trays ${ }^{20}$ as previously mentioned.

The Maleta tray contains a sluice chamber below the actual tray that collects the liquid holdup during the liquid flow period. When a new vapour flow period is initiated the sluice chamber opens in the bottom and closes in the top, thus allowing the liquid holdups to drain to the stage below, but not further down and thereby avoid back-mixing. 
The sluice chambers are opened and closed by the pressure fluctuations from turning the vapour flow on and off. The sequential draining can be achieved by using the COPS (Cyclically Operated Perforated Sheet) trays ${ }^{27}$. The COPS trays are opened and closed one by one, starting from the bottom, using pneumatics, which also means that with the sequential method of draining it is not necessary to interupt the vapour flow.

The difference in the two draining methods is summarised in Table 1 and Figure 1 shows how the simplified trays behave during VFP and LFP when the trays are drained and filled.

[Table 1 about here.]

[Figure 1 about here.]

In general the current models available are all mainly intended for a conceptual short-cut design modelling and preliminary studies of a cyclic distillation column, most of which do not describe the energy transfer between liquid and vapour. Hence, there is a lack of a energy and mass balance based stage model that can be used for rigorous simulation. With the energy transfer included an expression for the time dependent vapour flow rate can be set up. A more general stage model would further make it possible to include multiple feed and/or side draw locations as well as incorporate energy terms for example from reaction or mixing.

The purpose of this paper is to develop a general stage model that can be used for rigorous simulation of a cyclic dIstillation process by including both mass and energy balances in the model and possibility of multiple feed stages, side draw and additional energy at each stage. This model is for simultaneous drained cyclic distillation only, since this is the most mature technique and widely studied in literature. The proposed stage model will be equivalent to the well-known MESH equation model for conventional distillation ${ }^{29}$.

The model presented in this work is versatile in the sense it can account for different scenarios, which previous models could not. For example, a column with multiple feed and side draws, a column where the vapour flow changes significantly, high changes in stage temperature during VFP or when additional heat is added to a stage (or multiple stages).

This paper is organised with first a general description of a cyclic distillation process is given, followed by the model development, where the proposed model is presented. The model implementation, analysis and possible model 
variations are then presented and discussed. For different case studies, the performance of the proposed model is compared to the current state-of-the-art model. The performance of the two models is analysed in both quasistationary steady-state and open loop dynamic simulations. Finally, a discussion regarding the control of a cyclic distillation process as well as discussion of the model limitations are given.

\section{(1) Process description}

The general principle in the cyclic operation of a distillation process is dividing the process in two periods that together 
process, such as the combined mass and energy transfer. Both the mass and energy transfer on each tray, as well as disturbances can be described with the developed model and it is thus an equivalent to the well-known MESH equation model for cyclic distillation. The proposed model do not incorporate momentum balances and thus neither dynamic nor static pressure effects. The reason is that sufficient data and details of the tray design to justify this development is currently not available.

\section{Assumptions}

The following assumptions are made to simplify the model development:

- Equilibrium between vapour exiting a tray and the liquid holdup on the tray.

No back-mixing of liquid holdups.

Liquid feed and reflux is added during LFP. Vapour feed is added during VFP.

- Negligible vapour holdup.

- Constant pressure (negligible pressure drop).

The displacement of liquid holdups is instantaneous during LFP.

Side draws are removed during LFP.

Mass and heat transfer between phases only occurs during VFP.

No heat of mixing.

Negligible heat loss.

One of the main assumptions here is that vapour feed is only introduced during the VFP and liquid feed only during the LFP. For saturated liquid or vapour feeds, this is not an issue. However, if a high pressure liquid feed is introduced to a low pressure column, flash will occur after the feed enters the column and there would be both vapour and liquid flows at the same time. With the assumption of separated phase flows, it is not possible to simulate a simultaneous vapour and liquid feed. Therefore, it is assumed that the flashed vapour and the liquid is separated before it is introduced to the column, so that the liquid feed can be introduced during LFP and the flashed vapour during VFP. By assuming this it is possible to model the flash of the liquid feed, however, it is only reasonable for 
small amounts of flashed vapour. Generally, for a cyclic distillation process flashing of the feed is undesired, due to the separation of phase flows. Similar for a mixed feed with both liquid and vapour, e.g. a feed between the bubble and dew point, the vapour fraction of the feed is introduced during VFP and the liquid part of feed during LFP.

The remaining assumptions listed are often used for model development of both cyclic and conventional distillation $^{6,30}$.

\section{| Balance equations}

A general tray $n$ in the cyclic distillation column with simultaneous draining is depicted in Figure 2 for both the vapour flow period and the liquid flow period with corresponding inlets and outlets. This depiction is equivalent to a MESH stage in conventional columns, with the assumption of constant pressure (i.e. no pressure drop). During the VFP the vapour flow, compositions, temperatures and energies to the stage are all time dependent, whereas the liquid flow period is a discrete event, meaning the liquid holdups, compositions, temperatures and side draws are only dependent on the state variables after VFP.

For the model development the following variables are used: molar holdup of component $i$ in stage $n: M_{n, i}$, total molar holdup in stage $n: M_{n}$, vapour flow rate from stage $n: V_{n}$, liquid and vapour composition of component $i$ at stage $n: x_{n, i}$ and $y_{n, i}$ respectively. The liquid enthalpy at stage $n$ is denoted: $h_{n}$ and the vapour enthalpy is denoted: $H_{n}$. Any additional energy added to a stage is denoted $Q_{n}$ and any side draw $S_{n}$.

[Figure 2 about here.]

During the VFP, shown in Figure 2, there is only vapour flow and during LFP there is only liquid flow. Energy is only added to the stage during VFP and side draws are only removed during LFP.

During the VFP the mass and energy balances for tray $n=2, \ldots, N T-1$, counted from the top down, and component $i=1, \ldots, N C$ are:

VFP mole balance

$$
\frac{\mathrm{d} M_{n, i}(t)}{\mathrm{d} t}=V_{n+1}(t) y_{n+1, i}(t)-V_{n}(t) y_{n, i}(t)+V_{n+1}^{F}(t) y_{n+1, i}^{F}(t)
$$


With the initial conditions $M_{n, i}(0)=M_{n, i}^{0}$ for $i=1, \ldots, N C$.

VFP energy balance

$$
\frac{\mathrm{d} M_{n}(t) h_{n}(t)}{\mathrm{d} t}=V_{n+1}(t) H_{n+1}(t)-V_{n}(t) H_{n}(t)+V_{n+1}^{F}(t) H_{n+1}^{F}(t)+Q_{n}(t)
$$

With the initial conditions $h_{n}(0)=h_{n}^{0}$. This energy balance is used to describe the time dependent vapour flow rate.

During the liquid flow period the mass and energy balances for tray $n=2, \ldots, N T-1$ and component $i=1, \ldots, N C$

$$
M_{n, i}^{(L F P)}=M_{n-1, i}^{(V F P)}+M_{n-1, i}^{F}-S_{n} x_{n, i}^{(V F P)}
$$

The superscripts (LFP) and (VFP) denotes the end of the liquid flow and the vapour flow period respectively. This means the two variables $M_{n, i}^{(L F P)}$ and $M_{n, i}^{(V F P)}$ are the values of the stage holdups after the liquid and vapour flow periods respectively.

Tray $n=2$ is a special case since the liquid inlet is equal to the reflux, $L$, from the reboiler $M_{1, i}^{(V F P)}=L x_{1, i}^{(V F P)}$.

\section{LFP energy balance}

$$
M_{n}^{(L F P)} h_{n}^{(L F P)}=M_{n-1}^{V L F P)} h_{n-1}^{(V F P)}+M_{n-1}^{F} h_{n-1}^{F}-S_{n} h_{n}^{S D}
$$

\section{Reboiler and condenser}

The reboiler and condenser are special cases, however, the model equations can be written in a similar fashion where $V_{1}=V_{N T+1}=0$. During the VFP the model equations, with the assumptions of no feed, for the condenser $(n=1)$ and reboiler $(n=N T)$ and components $i=1, \ldots, N C$ can be written:

This article is protected by copyright. All rights reserved. 
VFP mole balances for $n=1$ and $n=N T$

$$
\begin{aligned}
\frac{\mathrm{d} M_{1, i}(t)}{\mathrm{d} t} & =V_{2}(t) y_{2, i}(t) \\
\frac{\mathrm{d} M_{N T, i}(t)}{\mathrm{d} t} & =-V_{N T}(t) y_{N T, i}(t)
\end{aligned}
$$

With the initial conditions $M_{1, i}(0)=M_{1, i}^{0}$ and $M_{N T, i}(0)=M_{N T, i}^{0}$ for $i=1, \ldots, N C$.

VFP energy balances for $n=1$ and $n=N T$

$$
\begin{gathered}
\frac{\mathrm{d} M_{1}(t) h_{1}(t)}{\mathrm{d} t}=V_{2}(t) H_{2}(t)+Q_{1}(t) \\
\frac{\mathrm{d} M_{N T}(t) h_{N T}(t)}{\mathrm{d} t}=-V_{N T}(t) H_{N T}(t)+Q_{N T}(t)
\end{gathered}
$$

With the initial conditions $h_{1}(0)=h_{1}^{0}$ and $h_{N T}(0)=h_{N T}^{0}$. The condenser and reboiler duties are denoted as $Q_{1}(t)=$ $Q_{C}(t)$ and $Q_{N T}(t)=Q_{R}(t)$ respectively.

LFP mole balances for $n=1$ and $n=N T$

$$
\begin{aligned}
& M_{1, i}^{(L F P)}=M_{1, i}^{(V F P)}-(D+L) x_{1, i}^{(V F P)} \\
& M_{N T, i}^{(L F P)}=M_{N T, i}^{(V F P)}+M_{N T-1, i}^{(V F P)}-B x_{N T, i}^{(V F P)}
\end{aligned}
$$

LFP energy balances for $n=1$ and $n=N T$

$$
\begin{aligned}
& M_{1}^{(L F P)} h_{1}^{(L F P)}=h_{1}^{(V F P)}\left(M_{1}^{(V F P)}-(D+L)\right) \\
& M_{N T}^{(L F P)} h_{N T}^{(L F P)}=M_{N T_{1}}^{(V F P)} h_{N T-1}^{(V F P)}+h_{N T}^{(V F P)}\left(M_{N T}^{(V F P)}-B\right)
\end{aligned}
$$

Here the distillate is denoted $D$, the reflux $L$ and the bottom product flow rate $B$.

This article is protected by copyright. All rights reserved. 


\section{| Summation and equilibrium equations}

As for the MESH equations ${ }^{29}$, it is necessary to ensure that the vapour and liquid mole fractions sum up to one and that equilibrium is reached on each stage for each component. The summation equations for the vapour and the liquid phase for stage $n=1, \ldots, N T$ are:

$$
\begin{aligned}
& \sum_{i=1}^{N C} y_{n, i}-1=0 \\
& \sum_{i=1}^{N C} x_{n, i}-1=0
\end{aligned}
$$

The phase equilibrium equation for component $i=1, \ldots, N C$ and stage $n=1, \ldots, N T$ is:

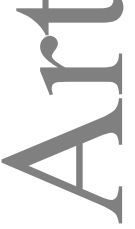

$$
y_{n, i}-K_{n, i} x_{n, i}=0
$$

Where $K_{n, i}$ is the separation factor.

These equations are required during both VFP and LFP. With the mass and energy balances, as well as the summation and equilibrium equations, an equivalent model to the MESH equation model can be set up.

\section{Constitutive equations}

For any given application of the presented model, pure component parameters and mixture specific relations are necessary. The constitutive equations for these used in this work are presented below.

\section{Vapour-liquid equilibrium}

With the assumption of ideal vapour phase the modified Raoult's law can be used to find the relation between the vapour and liquid compositions.

$$
y_{n, i} P=x_{n, i} P_{n, i}^{s a t} \gamma_{n, i}
$$

This article is protected by copyright. All rights reserved. 
Equation (16) is a special case of equation (15), where the vapour phase is assumed ideal and the liquid phase can be described with the activity coefficients. Hence, the separation factor will be defined as: $K_{n, i}=P_{n, i}^{s a t} \gamma_{n, i} / P$. The activity coefficient for the liquid phase can be determined by a suitable activity coefficient model. For an ideal liquid it follows that $\gamma_{n, i}=1$. A commonly used activity coefficient model for a mixture with a single liquid phase is the Wilson equation ${ }^{31,32}$. The vapour pressure must be determined from a vapour pressure equation.

\section{| Enthalpies}

The enthalpy can be found from a reference enthalpy, temperature and the specific heat capacity. In the following it is assumed that the specific heat capacity, $C_{P, i}^{V}$, is temperature independent. With the assumption of temperature independent specific heat capacity the vapour enthalpy of component $i$ on stage $n$ can be written as:

$$
H_{n, i}(t)=H_{i}^{\circ}+\int_{T_{r e f}}^{T_{n}(t)} C_{P, i}^{V} d T=h_{i}^{\circ}+C_{P, i}^{V}\left(T_{n}(t)-T_{r e f}\right)
$$

The proposed mass and energy balance model can be implemented with a general $C_{P, i}^{V}$ expression. For the case studies in this paper temperature independent specific heat capacities were used. Furthermore, the reference enthalpy is chosen arbitrarily, here assumed to be zero, and the reference temperature is chosen to be $T_{r e f}=298 \mathrm{~K}$. The values of the reference enthalpy, and corresponding reference temperature, can be chosen arbitrarily since it cancel out in the energy balances. In the following the reference enthalpy, $H_{i}^{\circ}=0$, is inserted in the general expressions for the enthalpies. The summation of the component contributions gives the vapour phase enthalpy for stage $n$, denoted C $H_{n}(t)$.

$$
H_{n}(t)=\sum_{i=1}^{N C} y_{n, i}(t)\left(C_{P, i}^{V}\left(T_{n}(t)-T_{b, i}\right)\right)
$$

As the heat of mixing is neglected. The liquid enthalpy can found as the vapour enthalpy of component $i$ at boiling point minus the heat of vaporisation ${ }^{4,33}$.

$$
h_{n}(t)=\sum_{i=1}^{N C} x_{n, i}(t)\left(C_{P, i}^{V}\left(T_{n}(t)-T_{r e f}\right)-\Delta H_{\text {vap }, i}^{\circ}\right)
$$




\section{Tray hydraulics}

The vapour flow rates throughout the column height can be found from the energy balance during the VFP in equation

(2). Inserting the terms for enthalpies and the mass balances gives:

$$
V_{n}(t)=\frac{1}{g(n, n, t)}\left[V_{n+1}(t) g(n, n+1, t)+V_{n+1}^{F}(t) g^{F}(n, n+1, t)-M_{n}(t) \sum_{i=1}^{N C} x_{n, i}(t) C_{P, i}^{V} \frac{\mathrm{d} T_{n}(t)}{\mathrm{d} t}+Q_{n}\right]
$$

Which consists of terms regarding the inlet vapour flow from below, the vapour feed (if any), the liquid holdup enthalpy

and the energy added (or removed) to the stage. It should be noted that this vapour flow rate is time dependent,

- Since it depends on the equilibrium composition and temperature and the change in these over time. The expression 13 $g\left(n_{a}, n_{b}, t\right)$, in units of $\mathrm{J} / \mathrm{mol}$, describes the difference in the vapour enthalpy $H_{n_{b}}(t)$ and the liquid enthalpy $h_{n_{a}}(t)$ and is defined as:

$$
\begin{aligned}
g\left(n_{a}, n_{b}, t\right)=H_{n_{b}}(t)-h_{n_{a}}(t)+M_{n_{a}}(t)\left[-\frac{T_{n_{a}}(t)}{M_{n_{a}}^{2}(t)} \sum_{i=1}^{N C} C_{P, i}^{V}\left(M_{n_{a}}(t) y_{n_{b}, i}(t)-M_{n_{a}, i}(t)\right)\right. & \\
& \left.+\sum_{i=1}^{N C} \frac{C_{P, i}^{V} T_{r e f}+\Delta H_{v a p, i}^{\circ}}{M_{n_{a}^{2}}(t)}\left(M_{n_{a}}(t) y_{n_{b}, i}(t)-M_{n_{a}, i}(t)\right)\right]
\end{aligned}
$$

Here $n_{a}$ and $n_{b}$ can either be equal, and thus describe the same stage, or $n_{b}=n_{a}+1$ in which case $g\left(n_{a}, n_{b}, t\right)$ 1 describes the enthalpy difference between the liquid holdup and the inlet vapour to stage $n_{a}$.

A similar expression for the vapour flow rate can be set up for the reboiler.

$$
V_{N T}(t)=\frac{Q_{B}(t)-M_{N T}(t) \sum_{i=1}^{N C} x_{N T, i}(t) C_{P, i}^{V} \frac{\mathrm{d} T_{N T}(t)}{\mathrm{d} t}}{g(N T, N T, t)}
$$

The total condenser has a vapour flow rate of zero. The temperature derivative, $\mathrm{d} T_{n}(t) / \mathrm{d} t$, is found from the modified Raoult's law in equation (16). For any given mixture, $1-\sum_{i=1}^{N C} y_{n, i}=0$. This can be rewritten with the modified Raoult's law, and can be defined as a function $f$. In the following it is assumed the function $f$ is only dependent on 
the temperature and component holdups on the tray $n$.

$$
f=1-\sum_{i=1}^{N C} x_{n, i} \gamma_{n, i} \frac{P_{n, i}^{s a t}}{P}=0
$$

Here the function $f$ is dependent on the liquid holdup of all components and the tray temperature. The derivative of $f$ with regards to time, with the assumption of $f$ only being dependent on temperature and component holdups, can be written:

$$
\frac{\mathrm{d} f(t)}{\mathrm{d} t}=\frac{\partial f(t)}{\partial T_{n}(t)} \frac{\mathrm{d} T_{n}(t)}{\mathrm{d} t}+\sum_{i=1}^{N C} \frac{\partial f(t)}{\partial M_{n, i}(t)} \frac{\mathrm{d} M_{n, i}(t)}{\mathrm{d} t}=0
$$

From this the derivative $\mathrm{d} T_{n}(t) / \mathrm{d} t$ can be isolated. The derivative $\mathrm{d} M_{n, i}(t) / \mathrm{d} t$ can be found from the mole balance (equation (1)) and the terms $\partial f(t) / \partial T_{n}(t)$ and $\partial f(t) / \partial M_{n, i}(t)$ from the modified Raoult's law in equation (16), when the activity coefficient model is known.

The liquid flow for tray $n$ is the same as the holdup on tray $n-1$ after a VFP, with the addition of any liquid feed and removal of any side draws. This is what is also shown in the mole balance during the LFP in equation (3).

\section{Duties}

The required condenser and reboiler duties can be found from the differences in vapour and liquid enthalpies:

$$
\begin{aligned}
& Q_{C}(t)=V_{2}(t)\left(H_{2}(t)-h_{1}(t)\right) \\
& Q_{R}(t)=\frac{M_{N T}^{0} \cdot B R}{t_{V F P}}\left(H_{N T}(t)-h_{N T}(t)\right)
\end{aligned}
$$

The condenser is a total condenser, meaning all the inlet vapour condenses, whereas the reboiler is a partial reboiler, meaning only a fraction of the holdup is reboiled. This fraction is defined by the boilup ratio, $B R$, which is a measure of the average vapour flow from the reboiler during VFP.

This article is protected by copyright. All rights reserved. 


\section{Periodicity condition}

To ensure a quasi-stationary steady-state is reached the following two conditions must be satisfied, where $M_{n}(t)$ is the total molar holdup in stage $n$ at time $t$.

$$
\begin{aligned}
& L=M_{1}\left(t_{V F P}\right)-M_{1}(0)-D \\
& B=M_{N T}\left(t_{V F P}\right)+M_{N T-1}\left(t_{V F P}\right)-M_{N T}(0)
\end{aligned}
$$

These two relations will ensure the total liquid holdups in the condenser and reboiler respectively are the same after

- 1 each LFP. With the implementation of these periodicity conditions, it is assumed the condenser and reboiler holdups 13 are perfectly controlled by the reflux and bottom product flow rate respectively.

\section{Holdups}

The sum of component holdups for a given stage is the total molar holdup, $M_{n}(t)$ :

$$
M_{n}(t)=\sum_{i=1}^{N C} M_{n, i}(t)
$$

Furthermore, the component holdup is equal to the product of the total holdup and the liquid molar fraction.

$$
M_{n, i}(t)=M_{n}(t) x_{n, i}(t)
$$

\section{Feed stages}

It is assumed that all the liquid feed is added during the LFP to tray $n$ and is, along with the holdup on tray $n$, drained to tray $n+1$ before the next vapour flow period. Any vapour feed that is added to the column is added during the entirety of VFP. The vapour is added above the liquid holdup on tray $n$ so the vapour feed mixes with the vapour from tray $n$.

If the feed temperature is above the bubble point, a flash calculation with known column pressure and feed enthalpy can be made. This is done to find the amount of liquid that is flashed and the respective temperature 
and compositions in the vapour and liquid phases. The flashing of feed is described previously. If the liquid feed is subcooled, i.e. below dew point, cold liquid will enter the column. When this cold feed mixes with the feed tray holdup, the stage temperature is decreased below bubble point. No mass transfer will occur when a tray temperature is below the bubble point, but the liquid is heated by the rising vapour until the bubble point is reached.

\section{| Temperature deviations}

As mentioned above, the feed temperatures can deviate from bubble point. However, the tray (or stage) temperatures for the liquid holdup might also deviate from the bubble point. If the tray temperature is too high, flash of the liquid will occur. It is assumed this will happen during LFP, after the mixing in the feed stages and reboiler has occurred. On the other hand if the temperature is too low, then no mass transfer will occur and the liquid holdup must be heated by the vapour coming from the stage below. This is assumed to occur during the VFP, since no vapour flow is present during the LFP. The tray and column material are assumed to not have any effect on the liquid holdup temperature. If the stage temperature is too low, it follows that the vapour flow period must be long enough, in order to ensure the liquid holdup is heated to the bubble point before mass transfer can occur.

\section{Model implementation, framework and analysis}

Both the mass balance model by Pătruţ ${ }^{6}$ and the proposed mass and energy balance model have been implemented in MATLAB ${ }^{\circledR}$. The model framework is shown in Figure 3.

[Figure 3 about here.]

In step 1-2 the problem is defined and the relevant properties for the given species and mixture is found in literature or in a database. As part of the problem definition, the model complexity is also defined (see Table 4). In step 3, the column is designed and the number of trays, initial conditions, feed location(s) and side draw(s) are specified. The cyclic distillation specific parameters, time periods for the VFP and LFP, as well as number of cycles simulated are chosen in step 4 and the rigorous dynamic model is solved. If the results are not satisfactory, the model parameters must be reevaluated. First it is evaluated whether the number of cycles or VFP and LFP times are too high or low. If this is not the case, then column design is verified, and finally the choice of VLE model and pure component/binary interaction parameters can be reconsidered.

This article is protected by copyright. All rights reserved. 
In the implementation of the models, the VFP and LFP are conveniently solved separately. One way to do this is to solve the VFP first, with suitable initial values. After this the algebraic equations for LFP can be solved, since the states after the LFP depend on the states after VFP. With the values after the LFP as initial values a new VFP can be solved and so forth any number of cycles can be simulated.

A model analysis, as described by Cameron and Gani ${ }^{34}$, is carried out for a single stage both in VFP and LFP. This model analysis is necessary to perform in order to ensure that the developed model is possible to solve. The separation factor, $K_{n, i}$, is in this analysis treated as a parameter, since the explicit temperature dependency is only known, when the appropriate VLE model has been selected.

The developed model for the vapour flow period contains $N_{e q s}^{V F P}=3+2 N C$ equations for a single stage, (1)-(2), (13)-(15). There are a total of $N_{V a r}^{V F P}=10+4 N C$ variables during VFP, which gives the following number of degrees of freedom: $N_{D o F}^{V F P}=7+2 N C$. In addition to the variables shown in Figure 2, the stage pressure, total holdup, individual holdups and duration of VFP are also variables. The feed and inlet variables, as well as the duration of VFP and the stage pressure are specified. This leaves the following variables to be calculated at each time step for stage $n$ and component $i: M_{n}(t), M_{n, i}(t), y_{n, i}(t), V_{n}(t), T_{n}(t)$. The liquid composition of the individual components can be found from the component holdups. The incidence matrix for the VFP is shown in Table 2.

[Table 2 about here.]

A degree of freedom analysis can also be done for the LFP. There are $N_{\text {eqs }}^{L F P}=3+2 N C$ equations, (3)-(4), (13)(15), for the LFP and $N_{\text {vars }}^{L F P}=10+4 N C$ variables, which gives the following number of degrees of freedom: $N_{D o F}^{L F P}=$ $7+2 N C$. The feed and inlet variables, as well as the duration of LFP and the stage pressure are specified, leaving the following variables to be calculated: $M_{n}^{(L F P)}, M_{n, i}^{(L F P)}, y_{n, i}^{(L F P)}, T_{n}^{(L F P)}, L_{n}^{(L F P)}$. Since the entire stage is completely drained during the LFP it follows that $M_{n}^{(L F P)}=L_{n}^{(L F P)} t_{L F P}$. The incidence matrix for the LFP is shown in Table 2.

[Table 3 about here.]

A total molar holdup balance can be used by summation of the component holdups in equation (1) for the VFP or equation (3) for the LFP. This can substitute either equation (14) or (13). 
For a cyclic distillation column with $N T$ stages and $N C$ components there are $N T(3+2 N C)$ equations to be solved for both the VFP and the LFP, with $N T(10+4 N C)$ variables each. This leaves a total of $2 N T(7+2 N C)$ variables that needs to be specified and $2 N T(3+2 N C)$ variables that can be calculated for each cycle, in order to be able to simulate any numbers of cycles.

The two incidence matrices do not have lower tri-diagonal forms, which means the model equations can not be solved sequentially ${ }^{34}$. The model must therefore be solved simultaneously and thus the differential equations and the algebraic constraints constitutes a DAE system of equations. This DAE system is not specific to cyclic distillation, but is generally seen in dynamic distillation processes as well as other complex chemical processes, where the ODEs describe the mass and energy balances and algebraic constraints describe the VLE. It is possible to simplify this DAE system to an ODE system by solving the algebraic constraints at each time step from the current states ${ }^{4,30,35,36}$. The solving of the ODE system is as follows: Initially for time $t=0$, the values of $T_{n}(0), M_{n, i}(0), M_{n}(0)$ and $x_{n, i}(0)$ are known from the initial conditions. The vapour flow rate and vapour compositions can then be calculated for $t=0$ using equations (15) and (20). Then the ODEs, equations (1)-(2), are calculated and for the next time step the algebraic equations can be solved again. With this simplification, by separating the ODEs from the algebraic constraints, a certain level of uncertainty is allowed in the solving for each time step. However, as long as the time steps are reasonably small, this should not give any significant deviations compared to solving the DAE system.

\section{Model variations}

The above energy and mass balance model is a general description that can be used for many applications. Table 4 how the features of the full model compared to some of the simplified alternatives. The developed model in Table 4 can readily be reduced to the mass balance model, proposed by Pătruţ ${ }^{6}$, by removing the energy balances, vapour feed terms and set the vapour flow rate constant. By removing the possibility of additional feed/side draws and energy to the stage and assume all stages are always at bubble point, the proposed model reduces to the currently available mass and energy balance model by Andersen et al. ${ }^{21}$. All the models are capable of handling multi-component mixtures with nonlinear equilibrium.

[Table 4 about here.]

In the developed model it is possible to include an extra energy term $Q_{n}$ (equation (2)). This energy term could be 
used to describe heat-integration, heat of mixing, reaction energy or any combination of these, which existing models are not developed for.

\section{Case studies}

In this section, case studies are performed with the intention to investigate the difference between the simple mass balance model and the proposed mass and energy balance model. Examples from Pătruţ et al. ${ }^{6}$ have been used for comparing the two models. The chosen case studies from Pătruţ et al. are: Ideal mixtures of benzene/toluene and benzene/toluene/o-xylene, and a non-ideal mixture of ethanol/n-pentanol. Furthermore, a non-ideal mixture of ethanol/methanol/water has also been analysed. The non-ideal mixtures are described by the Wilson activity coefficient model, with the binary interaction parameters found in Aspen Plus.

With the chosen case studies, both ideal and non-ideal binary and ternary mixtures will be investigated. All the simulation parameters for the case studies are shown in Table 5.

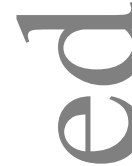

[Table 5 about here.]

There are currently no results, either from experimental studies or simulation software, available in literature for cyclic distillation with the tray design by Maleta et al. ${ }^{20}$, which can be used for validating the proposed model. In 2019 an experimental study with Maleta trays for a pilot scale cyclic stripper column for ethanol purification with air was presented ${ }^{25}$. However, this work is focused on a stripping process for removal of impurities and is therefore not applicable as a case for comparison for the cyclic distillation models discussed in this paper. Furthermore, the cyclic distillation process is not possible to simulate with existing tools in commercial simulation software. As there are no experimental data available from literature, or commercial simulations, for cyclic distillation it was decided to investigate the proposed model with the cases in Table 5. Three of the four cases that are analysed in this paper have previously been studied in another cyclic distillation modelling work by Pătruţ et al. ${ }^{6}$.

The chosen case studies, summarised in Table 5, are analysed in terms of differences between the mass balance model and the mass and energy balance model. First the differences in the cyclic behaviour is investigated for the 
case of benzene/tolene. Figure 4 shows 10 cycles for the benzene/toluene mixture, when using the mass model (light grey) and the proposed mass and energy balance model (dark grey).

[Figure 4 about here.]

In Figure 4 the quasi-stationary steady-state can be seen as the identical repeating cycles. There is a clear difference in the mass and the mass and energy balance models, for example the mass and energy balance model predicts higher purity top and bottom products. There is, however, no trend in the magnitude of change in the composition over the VFP over time, where the simple mass balance model predicts a higher change in the composition in stage 4 , it predicts a lower change in stage 7.

The main reason for this difference between the two models is the vapour flow rate. For the mass balance model it is assumed the vapour flow rates are constant over the period, shown in Table 5 . Whereas the flow rates are time dependent for the proposed mass and energy balance model. The vapour flow rate is dependent on the stage temperature as well as the liquid and vapour phase compositions. When the vapour flows up through a column and interact with the liquid holdups the two phases reaches an equilibrium, where there will be a transfer of moles

(1) between the phases. The time dependent vapour flow rate for the proposed model changes with the time derivative of the stage temperature, which in turn depends on the change in composition and equilibrium. It follows that a time dependent vapour flow rate will be more important for long vapour flow periods, since for a short VFP the change in $V_{n}(t)$ will be low. Furthermore, a mixture with high differences in volatility will experience a higher degree of mass transfer between the vapour and liquid phases. In general large temperature changes over a cycle would result in large changes in the vapour flow rate. This will in turn also mean a high degree of change in composition and temperature over time, and therefore a time dependent vapour flow rate is necessary for high fidelity simulations.

The differences in the mass and the mass and energy balance models are further investigated in the following comparisons between the quasi-stationary steady-states for the simple mass balance model and the full mass and energy balance model for the four cases in Table 5. These comparisons are shown in Figure 5. Shown in the figure is the molar composition of each stage after a VFP with the cycles in quasi-stationary steady-state.

[Figure 5 about here.]

This article is protected by copyright. All rights reserved. 
There is a clear difference between using a simple mass balance model and an extended model with both mass and energy balances as is evident from the quasi-stationary steady-state plots in Figure 5 . For the two binary cases the mass and energy balance model shows a higher degree of separation than the mass balance model. This is due to the time dependent vapour flow rate as mentioned previously. In both cases it seems the columns are over-dimensioned when using the mass and energy balance model. This means that by using the mass and energy balance model, with a time dependent vapour flow rate, fewer trays are needed for the same process compared to the prediction from the mass balance model.

For the case with benzene/toluene/o-xylene there is also a clear difference between the two models. While the top and bottom compositions are similar, the column profile is not. The mid-boiling component, toluene, is predicted by the mass balance model to have the highest composition at stage 13 , while the mass and energy balance model predicts the highest composition at stage 12. This means if the mid-boiling component is desired to be removed as a side-product the two models would give two different optimal stages.

The last case, ethanol/methanol/water, does not seem to have any significant difference between the two models. The reason for this is the low vapour flow rate. For the mass balance it was set constant to 5 mol/s and for the mass and energy balance it was found to be between $5.53 \mathrm{~mol} / \mathrm{s}$ and $5.73 \mathrm{~mol} / \mathrm{s}$, on average for all stages around 5.57 $\mathrm{mol} / \mathrm{s}$. Since the vapour flow rates are very similar for the two models, the difference between the results is minor. Hence for this case with small changes in the vapour flow rate, as mentioned previously, the mass balance model can be used as a reasonable approximation. For comparison the vapour flow rate for the benzene/toluene case ranged from $37.49 \mathrm{~mol} / \mathrm{s}$ to $45.17 \mathrm{~mol} / \mathrm{s}$ over the stages, with an average of $41.20 \mathrm{~mol} / \mathrm{s}$. Here the time dependent vapour flow rate has a significant effect and the mass and energy balance should therefore be used. This can also be seen as the high difference between the compositions for the two models in Figure 5.

\section{Dynamic open loop disturbance response}

For the ethanol/methanol/water case in Table 5, with saturated liquid feed, the introduction of disturbances in the feed composition are investigated. $A \pm 5 \%$ change in the feed content of ethanol is introduced, while keeping the methanol feed composition constant. The condenser and reboiler content after each VFP for these disturbances and for the quasi-stationary steady-state are shown in Figure 6 for the simple mass balance model and the mass and 
energy balance model.

[Figure 6 about here.]

Both models, despite different quasi-stationary steady-states, have comparable response to the changes in the feed composition. The relative changes from the initial quasi-stationary steady-state to the new in ethanol composition are summarised in Table 6.

[Table 6 about here.]

The relative changes and dynamic response in quasi-stationary steady-states are similar for both models. The two models also showed similar quasi-stationary steady state profile as shown in the bottom plot in Figure 5 . This was due to the almost constant vapour flow rate for the mass and energy balance model. For the $\pm 5 \%$ disturbances in the ethanol feed composition, with the mass and energy balance model, the vapour flow rate was almost constant with a flow rate around $5.32-5.73 \mathrm{~mol} / \mathrm{s}$. Since the vapour flow rate was almost constant for the mass and energy balance model, it is as expected that the two models would show similar dynamic response as shown in Figure 6.

For the benzene/toluene case changes in the feed temperature have been investigated with the presented model. The composition of benzene in the top and bottom stage after VFP are shown in Figure 7 for the quasi-stationary steady-state with saturated liquid feed (black) and a $+5 \%$ (dark grey) and a $-5 \%$ (light grey) change in the feed temperature.

( )

[Figure 7 about here.]

When the feed temperature is increased to a value above the boiling point flash will occur. This means a fraction of the liquid will flash to vapour and will be introduced to the column during VFP as previously described. After the flash a new boiling point will be found. In this case for an equimolar benzene and toluene mixture at atmospheric pressure the saturation temperature is $365.24 \mathrm{~K}$ and the temperature after a $5 \%$ increase followed by flash is $365.62 \mathrm{~K}$. This is a small change in temperature, however, the vapour feed goes from $0 \mathrm{~mol} / \mathrm{s}$ to $1.89 \mathrm{~mol} / \mathrm{s}$ over the 12 second duration of VFP. Increasing the feed temperature thus lowers the top concentration and increases the bottom concentration of benzene. In this work it is assumed that the flashed feed can be separated, allowing the liquid to be introduced 
during LFP and the flashed vapour during VFP. When the feed is flashed only a fraction of the total feed is introduced as liquid (93.94\%), which means less liquid holdup will be on the trays below the feed stage. The flashed vapour on the other hand will mix with the vapour from the feed stage and rise. However, it was found the flashed vapour had a lower composition of benzene than the vapour from below the feed location. This means a higher fraction of toluene will be in the vapour from the feed stage to the condenser and thus lower the concentration of benzene.

After a $5 \%$ decrease in the feed temperature to $346.98 \mathrm{~K}$, the composition of benzene changes drastically. It appears that when the temperature is decreased, the separation of benzene and toluene is highly affected as well. When the feed temperature is below the boiling point, the feed stage temperature is also decreased to below the boiling point after mixing, this means there is no mass transfer occurring until the liquid is heated.

-

\section{Operation and control of the cyclic distillation process}

The first studies for the control of a cyclic distillation process were made in the 20 th century ${ }^{16,37,38}$. These early studies investigated the use of a variable period control, for which $t_{V F P}$ was made a manipulated variable to control (1) the bottom product composition. More recently, Pătruţ et al. ${ }^{6}$ suggested a control of the temperatures near the top and bottom at the end of VFP. The reflux and vapour flow rate are then manipulated by used of discrete PIcontrollers. Andersen et al. ${ }^{21}$ also presented a discrete PI-controller based on the work by Matsubara et al. ${ }^{37}$, with 1 the reboiler duty as the manipulated variable and bottom product concentration as controlled variable. All these previously proposed controller configurations for cyclic distillation present simple control strategies based on the Codels available at the time.

In order to develop a control strategy for the cyclic distillation process the manipulated and controlled variables must be identified ${ }^{39}$. The model presented by Pătruţ et al. ${ }^{6}$ has the following manipulated variables: feed rate, top and bottom rates, reflux rate and the duration of the VFP and LFP. The proposed model has the same manipulated variables with the addition of the boilup rate. With the boilup rate as a manipulated variable it is possible to manipulate the vapour flow rate, which as shown previously in Figure 5 has a significant effect on the separation. There is also the possibility of side draws as well as multiple feed locations, which, if included, each present another manipulated 
variable. Furthermore, the mass and energy balance model can account for additional controlled variables, such as the time dependent temperature of each stage. With the model presented in this paper the feed temperature can be included as a disturbance as shown in Figure 7. The detailed design ofa new controller configuration is in itself an extensive task and is best treated in a separate study.

\section{Model limitations}

The proposed model is subject to some assumptions, one of which is the assumption of constant pressure in the column or in other words no pressure drop in the column. Including the pressure drop over each tray would require information about the column design specifications, i.e. the internals, the tray diameter and height of the liquid holdup. 1 In a cyclic operation with simultaneous draining the pressure would equalise in the column during the LFP while the pressure profile will build up dynamically over the VFP. Hence the time constant and magnitude for this pressure dynamics in relation to the length of the VFP will in the end determine if pressure drop effects can be ignored. Alternativ atively, a simpler method would be to set a specific static pressure drop per stage. In conventional distillation trays, with downcomers, the liquid height is limited by the weir height. In cyclic distillation trays there are no downcomers, and thus no physical limit on the height of the liquid, however, the pressure drop is still affected by the liquid level. In the cases mentioned in this paper, the assumption of no pressure drops physically means that it is assumed the liquid height on the trays is low enough to not have a significant effect on the pressure drop over the tray. The assumption of no pressure drop is often used in the modelling of columns, since the pressure drops are generally low. If pressure drops were included, it would make the modelling more realistic, however, it would also require a more comprehensive model to predict the pressure on each stage. With such a comprehensive process model it would also be possible to perform more realistic control studies 30,40 .

Another important assumption is the assumption of equilibrium trays. This means the vapour exiting a tray is in equilibrium with the liquid holdup. This is rarely the case and often a point efficiency less than unity is introduced to account for this. An assumption of point efficiency equal to one is suitable for modelling purposes to simplify the implementation and calculations. When designing a column the assumption of equilibrium stages will most likely 
under-dimension the column and the desired separation is not achieved with the calculated number of equilibrium trays $^{41}$.

Despite the exclusion of pressure drop and non-equilibrium stages, the proposed model is still more widely applicable for different case studies for detailed simulation, design or control purposes than the existing models available. With the proposed model it is furthermore possible to directly add the effect of heats of reaction in the energy balances, thereby making it possible to investigate reactive distillation cases.

With the energy balances included in the model it is possible to model the changes in the temperature over time, thus making it possible to use the actual temperatures, not necessarily the bubble point temperatures, as controlled variables in a control configuration. The energy balances also allow changing the vapour flow rate by using the energy to the reboiler as a manipulated variable.

As mentioned previously the assumption of separate phase flow rates leads to an assumption of a flash of feed that would be difficult to implement in real life. However, this assumption is necessary in order to able to simulate the process. As long as the amount of vapour that is released after the flash is small or the duration of the VFP is short, this assumption is reasonable.

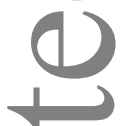

\section{Conclusion}

Operating a distillation process in cyclic mode has previously been shown to give higher throughput, higher separation

performance and reduced energy consumption in reboiler and condenser. The previous modelling work for cyclic

distillation have mainly been mass balance based for short-cut design purposes. Therefore, a stage model for mass and energy transfer has been proposed, including considerations of how the vapour flow rate changes for each stage over time. It is a highly versatile model for cyclic distillation processes, with simultaneous draining of the trays, that can be used for many different cases with the possibility of multiple liquid and/or vapour feed and side draws.

Comparisons of the proposed mass and energy transfer model and the current mass transfer model for different cases showed that for significant changes in the vapour flow rate over the column would lead to different column profile predictions, and therefore also different column designs. An example of this is the case of benzene/toluene, 
where the change in vapour flow rate was found to be significant, the proposed mass and energy balance model predicted that high purity products could be reached with fewer stages than predicted by the mass transfer model. On the other hand, for the ethanol/methanol/water case, where there was a small change in vapour flow rate, the column profile predicted by the mass transfer and the mass and energy transfer models were similar.

The proposed mass and energy balance stage model can account for additional manipulated variables, of which the boilup rate is an important one. With the boilup rate as a manipulated variable it is possible to adjust the vapour flow rate, which as mentioned has a significant effect on the separation. Furthermore, the time dependent stage temperatures can be defined as controlled variables and the feed temperature as a disturbance, which was shown for the benzene/toluene case. As for the quasi-stationary steady-state simulations, the dynamic responses to disturbances showed that the vapour flow rate is important. If there is no significant change in the vapour flow rate over the column, then the dynamic responses for a change in the feed composition for the mass balance model and the proposed model were similar, as shown for the ethanol/methanol/water case.

[Table 7 about here.]

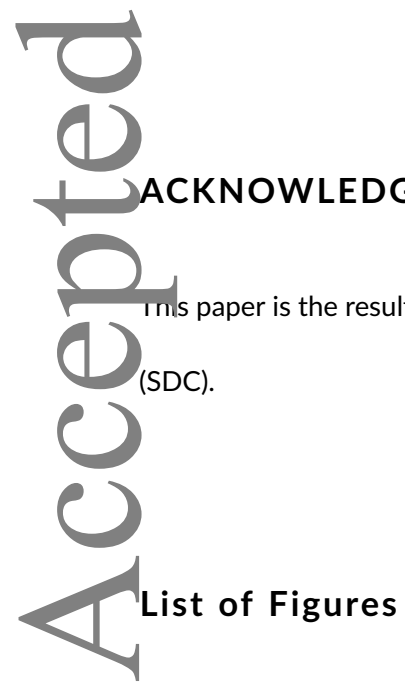

1 Maleta tray (top) ${ }^{20}$ during (a) VFP, (b) draining to sluice chamber during LFP and (c) VFP with draining from sluice chamber and filling of tray below. COPS tray (bottom) ${ }^{27}$ during (d) VFP, (e) draining of tray,

(f) filling of tray.

This article is protected by copyright. All rights reserved. 
2 Inlets and outlets to stage $n$ in a cyclic distillation column with simultaneous draining during VFP (top)

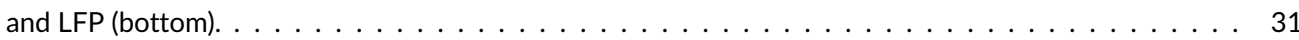

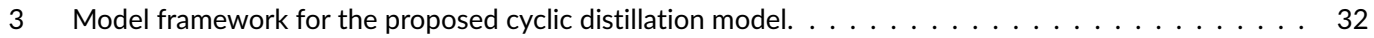

4 Stages in quasi-stationary steady-state for mass balance model (light grey) and mass and energy balance model (dark grey) for an ideal mixture of benzene/toluene. . . . . . . . . . . . . . . . . . . 32

5 Stage compositions after VFP for the cases in Table 5 for the mass balance model (light grey) and the mass and energy balance model (dark grey) in quasi-stationary steady-state. . . . . . . . . . . .

6 EtOH compositions in condenser (top) and reboiler (bottom) after VFP in quasi-stationary steady-state (black) and for $+5 \%$ (dark grey) and $-5 \%$ (light grey) changes in the feed EtOH composition, using the simple mass balance model (left) and the extended mass and energy balance model (right). . . . . . . .

7 Benzene composition in condenser (top) and reboiler (bottom) for saturated liquid feed (black), $+5 \%$ in

feed temperature (dark grey) and $-5 \%$ in feed temperature (light grey). . . . . . . . . . . . . . 34

\section{PERENCES}

1. Sholl DS, Lively RP. Seven chemical separations to change the world. Nature News 2016;532:435-437.

2. Kiss AA. Advanced Distillation Technologies: Design, Control and Applications. (1st ed. Chichester, UK: John Wiley \& Sons, Ltd; 2013.

3. Kiss AA. Distillation technology - still young and full of breakthrough opportunities. Journal of Chemical Technology and Biotechnology 2014;89:479-498.

4. Bisgaard T, Huusom JK, Abildskov J. Modeling and analysis of conventional and heat-integrated distillation columns. AIChE Journal 2015;61:4251-4263.

This article is protected by copyright. All rights reserved. 
5. Cannon MR. Controlled Cycling Improves Various Processes. Industrial \& Engineering Chemistry 1961;53:629-629.

6. Pătruţ C, Bîldea CS, Liţa I, Kiss AA. Cyclic distillation - Design, control and applications. Separation and Purification Technology 2014;125:326-336.

7. Bîldea CS, Pătruţ C, Jørgensen SB, Abildskov J, Kiss AA. Cyclic distillation technology - A mini-review. Journal of Chemical Technology and Biotechnology 2016;91:1215-1223.

8. Lewis WK. Rectification of Binary mixtures. Industrial \& Engineering Chemistry 1936;28:399-402.

9. Robinson RG, Engel AJ. An analysis of controlled cycling mass transfer operations. Industrial and Engineering Chemistry 1967;59:22-29.

10. Mcwhirter JR, Cannon MR. Controlled Cycling Distillation:... in a Packed-Plate Column. Industrial and Engineering Chemistry 1961;53:632-634.

11. McWhirter JR, Lloyd WA. New look at distillation - 5. Controlled cycling in distillation and extraction. Chemical Engineering Progress 1963;59:58-63.

12. Schrodt VN, Sommerfeld JT, Martin OR, Parisot PE, Chien HH. Plant-scale study of controlled cyclic distillation. Chemical Engineering Science 1967;22:759-767.

13. Chien HH, Sommerfeld JT, Schrodt VN, Parisot PE. Study of Controlled Cyclic Distillation: II. Analytical Transient Solution and Asymptotic Plate Efficiencies. Separation Science 1966;1:281-317.

14. Furzer IA. Periodic cycling of plate columns. Chemical Engineering Science 1973;28:296-299.

15. Furzer IA. Periodic cycling of plate columns: Mass transfer with nonideal liquid draining. AIChE Journal 1979;25:600609.

16. Matsubara M, Nishimura Y, Watanabe N, Shimizu K. Periodic control of continuous distillation processes. Chemical Engineering Science 1975;30:1075-1083.

17. Baron G, Wajc S, Lavie R. Stepwise periodic distillation. Chemical Engineering Science 1980;35:859-865.

This article is protected by copyright. All rights reserved. 
18. Furzer IA. Steady state flow distributions in a plate column fitted with a manifold. Chemical Engineering Science 1980;35:1291-1298.

19. Szonyi L, Furzer IA. Periodic cycling of distillation columns using a new tray design. AIChE Journal 1985;31:1707-1713.

20. Maleta VN, Kiss AA, Taran VM, Maleta BV. Understanding process intensification in cyclic distillation systems. Chemical Engineering and Processing: Process Intensification 2011;50:655-664.

21. Andersen BB, Nielsen RF, Udugama IA, Papadakis E, Gernaey KV, Huusom JK, et al. Integrated Process Design and Control of Cyclic Distillation Columns. IFAC Advanced Control of Chemical Processes 2017;51:542-547.

22. Kiss AA, Maleta VN. Cyclic distillation technology - A new challenger in fluid separations. Chemical Engineering Transactions 2018;69:823-828.

23. Maleta BV, Shevchenko A, Bedryk O, Kiss AA. Pilot-scale studies of process intensification by cyclic distillation. AIChE Journal 2015;61:2581-2591.

24. Nielsen RF, Huusom JK, Abildskov J. Driving Force Based Design of Cyclic Distillation. Industrial and Engineering Chemistry Research 2017;56:10833-10844.

25. Maleta B, Bedryk O, Shevchenko A, Kiss AA. Pilot-scale experimental studies on ethanol purification by cyclic stripping. AIChE Journal 2019;65:1-7.

26. Nielsen, Adem A R ; Álvarez, Elena Carrasquer; Carlsen, Niels F V ; Azizi, Haroon-U -R ; Jørgensen, Sten Bay; Abildskov J. Analysis and Evaluation of Periodic Separations Using COPS Trays. Chemical Engineering Transactions 2018;69:6.

27. Toftegård B, Clausen CH, Jørgensen SB, Abildskov J. New Realization of Periodic Cycled Separation. Industrial \& Engineering Chemistry Research 2016;55:1720-1730.

28. Wankat PC. Continuous Cyclic Distillation for Binary Solvent Exchange: The Batch Stack. Industrial and Engineering Chemistry Research 2018;57:16077-16083.

29. Wang JC, Henke GE. Tridiagonal Matrix for Distillation. Hydrocarbon Processing 1966;45:155-163. 
30. Skogestad S. Dynamics and control of distillation columns - A critical survey. Modeling, Identification and Control 1997;18:177-217.

31. Wilson GM. Vapor-Liquid Equilibrium. XI. A New Expression for the Excess Free Energy of Mixing. Journal of the American Chemical Society 1964;86:127-130.

32. Taylor R, Koodman HA. Composition Derivatives of Activity Coefficient Models (For the Estimation of Thermodynamic Factors in Diffusion). Chemical Engineering Communications 1991;102:87-106.

33. Biegler L, Grossmann I, Westerberg A. Systematic Methods of Chemical Process Design. 1 ed. Pearson Education; 1997.

34. Cameron I, Gani R. Product and Process Modelling: A Case Study Approach. (1st ed. Oxford, UK: Elsevier Science \& Technology Books; 2011.

35. Gani R, Ruiz CA, Cameron IT. A generalized model for distillation columns-I. Model description and applications. Computers and Chemical Engineering 1986;10:181-198.

36. Biegler LT, Damiano JJ, Blau GE. Nonlinear parameter estimation: A case study comparison. AIChE Journal 1986;32:2945.

37. Matsubara M, Nishimura Y, Watanabe N, Onogi K. Relay feedback periodic control of plate columns. Chemical Engineering Science 1982;37:753-758.

38. Dale EB, Furzer IA. Periodic cycling of plate columns. Control simulations and experiments. Chemical Engineering Science 1978;33:905-911.

39. Skogestad S. Control structure design for complete chemical plants. Computers and Chemical Engineering 2004;28:219234.

40. Mauricio-Iglesias M, Bisgaard T, Kristensen H, Gernaey KV, Abildskov J, Huusom JK. Pressure Control in Distillation Columns: A Model-Based Analysis. Industrial and Engineering Chemistry Research 2014;53:14776-14787.

41. Vishwakarma V, Schubert M, Hampel U. Assessment of separation efficiency modeling and visualization approaches pertaining to flow and mixing patterns on distillation trays. Chemical Engineering Science 2018;185:182-208.

This article is protected by copyright. All rights reserved. 


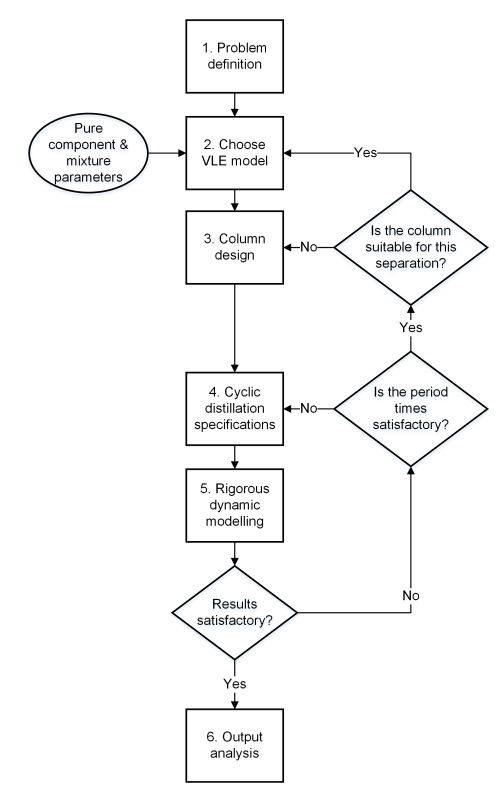

FIGURE 3 Model framework for the proposed cyclic distillation model.
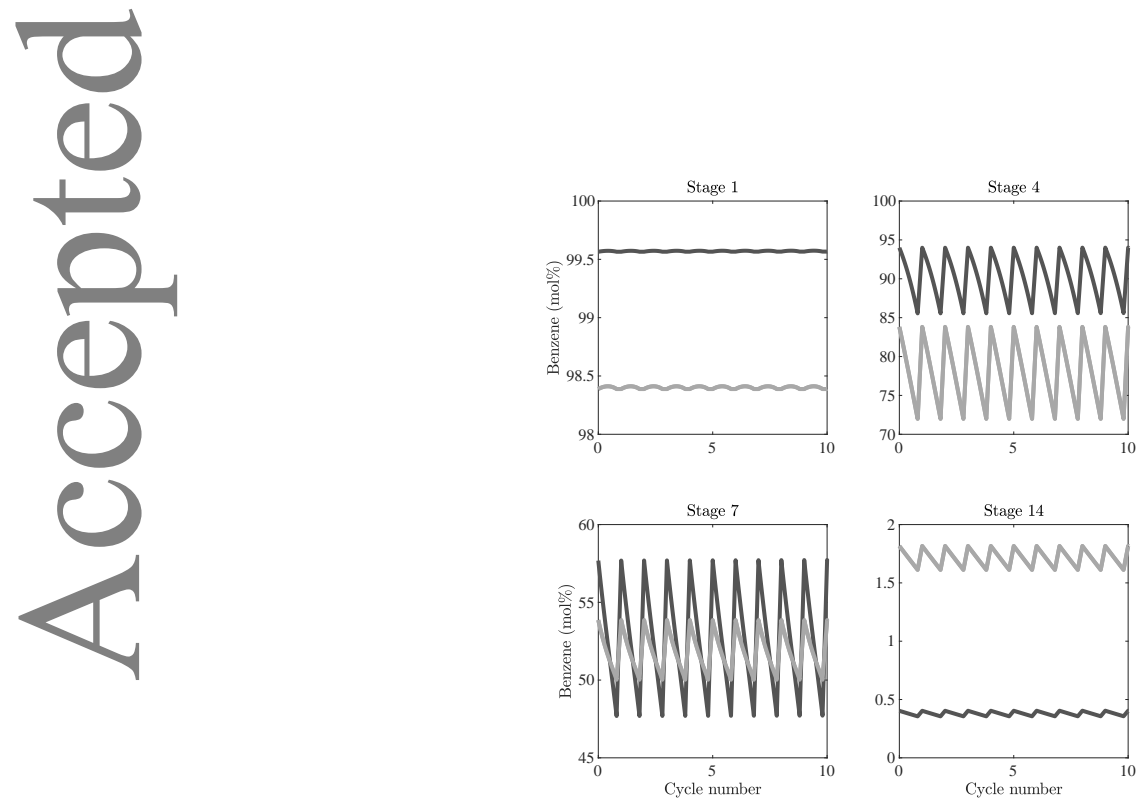

FIGURE 4 Stages in quasi-stationary steady-state for mass balance model (light grey) and mass and energy balance model (dark grey) for an ideal mixture of benzene/toluene.

This article is protected by copyright. All rights reserved. 

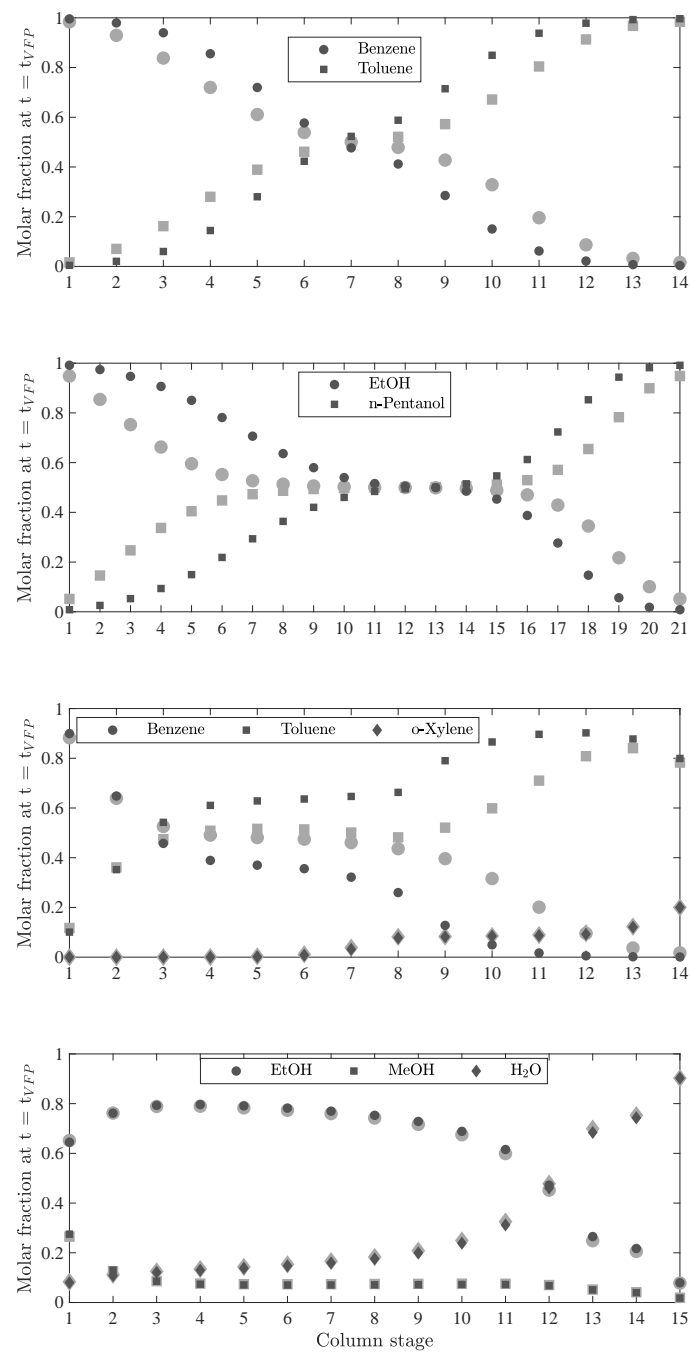

FIGURE 5 Stage compositions after VFP for the cases in Table 5 for the mass balance model (light grey) and the mass and energy balance model (dark grey) in quasi-stationary steady-state.

This article is protected by copyright. All rights reserved. 

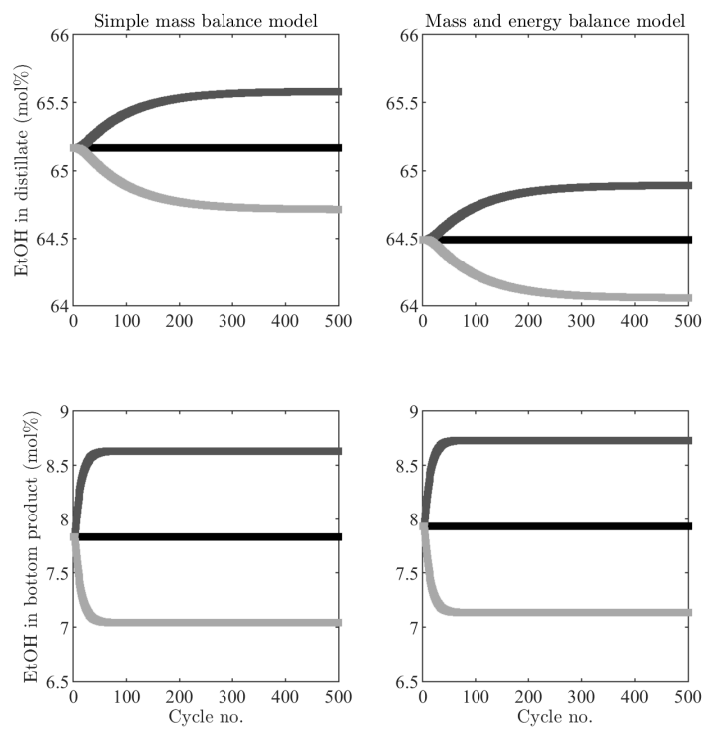

FIGURE 6 EtOH compositions in condenser (top) and reboiler (bottom) after VFP in quasi-stationary steady-state (black) and for $+5 \%$ (dark grey) and $-5 \%$ (light grey) changes in the feed EtOH composition, using the simple mass balance model (left) and the extended mass and energy balance model (right).
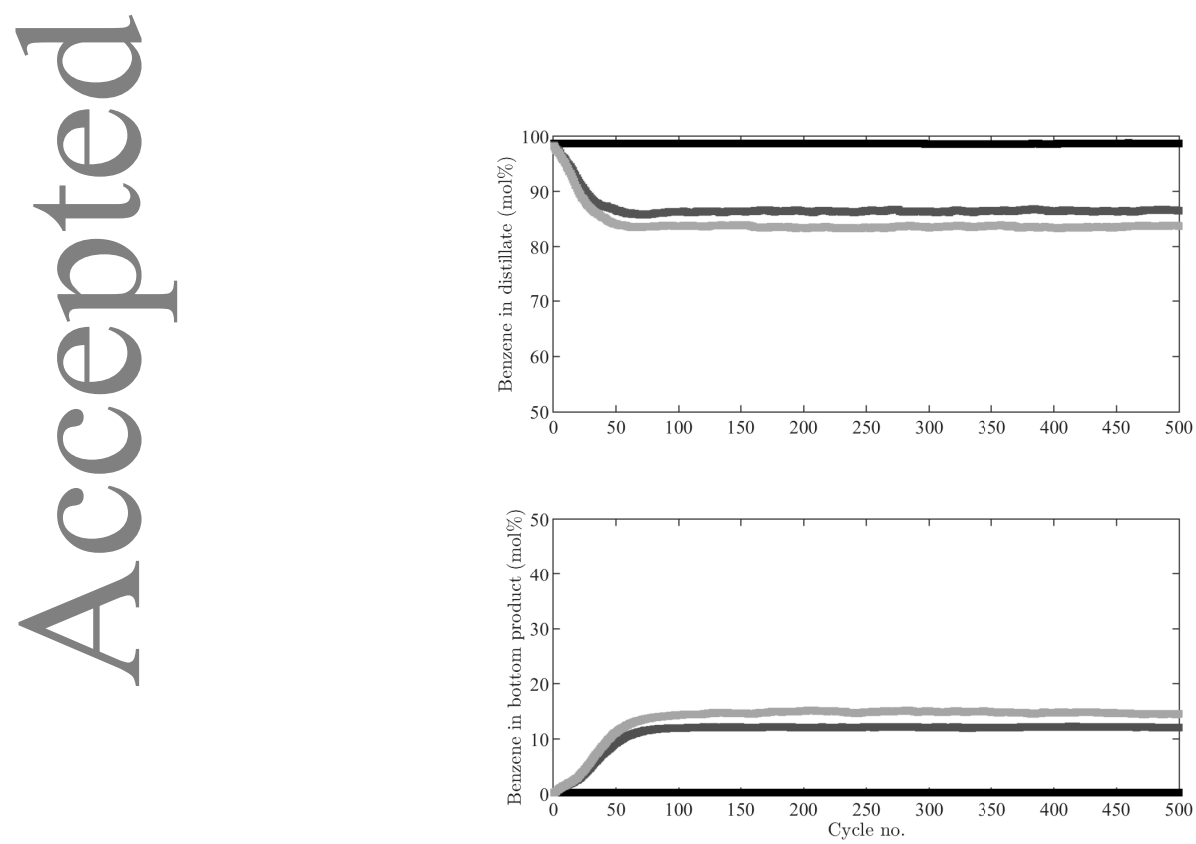

FIGURE 7 Benzene composition in condenser (top) and reboiler (bottom) for saturated liquid feed (black), $+5 \%$ in feed temperature (dark grey) and $-5 \%$ in feed temperature (light grey).

This article is protected by copyright. All rights reserved. 
TABLE 1 Differences in the two draining methods for cyclic distillation.

\begin{tabular}{|llll|}
\hline Draining method & Tray type & Vapour flow & Opening/closing mechanism \\
\hline Simultaneous & Maleta $^{20}$ & During VFP & Pistons \\
\hline Sequential & COPS $^{27}$ & During VFP and LFP & Pneumatics \\
\hline
\end{tabular}

TABLE 2 Incidence matrix for VFP.

\begin{tabular}{l|ccccc}
\hline VFP & $M_{n}(t)$ & $M_{n, i}(t)$ & $y_{n, i}(t)$ & $T_{n}(t)$ & $V_{n}(t)$ \\
\hline $\mathrm{Eq} \mathrm{(14)}$ & $\times$ & $\times$ & & & \\
\hline $\mathrm{Eq} \mathrm{(13)}$ & & & $\times$ & & \\
\hline $\mathrm{Eq} \mathrm{(15)}$ & $\times$ & $\times$ & $\times$ & $\times$ & \\
\hline $\mathrm{Eq} \mathrm{(1)}$ & $\times$ & $\times$ & $\times$ & & $\times$ \\
\hline $\mathrm{Eq} \mathrm{(2)}$ & $\times$ & $\times$ & $\times$ & $\times$ & $\times$
\end{tabular}

TABLE 3 Incidence matrix for LFP.

\begin{tabular}{l|ccccc}
\hline LFP & $M_{n}^{(L F P)}$ & $M_{n, i}^{(L F P)}$ & $y_{n, i}^{(L F P)}$ & $T_{n}^{(L F P)}$ & $L_{n}^{(L F P)}$ \\
\hline Eq (14) & $\times$ & $\times$ & & & \\
\hline Eq (13) & & & $\times$ & & \\
\hline Eq (15) & $\times$ & $\times$ & $\times$ & $\times$ & \\
\hline Eq (3) & $\times$ & $\times$ & $\times$ & & $\times$ \\
\hline Eq (4) & $\times$ & $\times$ & $\times$ & $\times$ & $\times$ \\
& & & & & \\
\hline
\end{tabular}

This article is protected by copyright. All rights reserved. 
TABLE 4 Features of the general model and simplified versions.

\begin{tabular}{llll}
\hline Feature & Full stage model & $\begin{array}{l}\text { Current mass } \\
\text { and energy bal- } \\
\text { ance model }{ }^{21}\end{array}$ & Mass balance model ${ }^{6}$ \\
\hline Mass transfer & Yes & Yes & Yes \\
\hline Heat transfer & Yes & Yes & No \\
\hline $\begin{array}{l}\text { Time dependent } \\
\text { vapour flow rate } \\
\text { based on the energy }\end{array}$ & Yes & (Yes) & No \\
transfer & & & \\
\hline $\begin{array}{l}\text { Vapour feed } \\
\text { Multiple feed }\end{array}$ & Yes & Yes & No \\
\hline $\begin{array}{l}\text { Side draws } \\
\text { Additional energy }\end{array}$ & Yes & No & No \\
term & & No & No \\
\hline $\begin{array}{l}\text { Tray temperatures } \\
\text { different than boil- }\end{array}$ & Yes & No & No \\
ing point & & No & No \\
\hline \begin{tabular}{l} 
Subcooled feed \\
\hline
\end{tabular} & Yes & No & No \\
\hline
\end{tabular}

TAB LE 5 Simulation parameters for the case studies.

\begin{tabular}{lllll} 
Parameter & Benzene/Toluene & Ethanol/n-Pentanol & $\begin{array}{l}\text { Benzene/Toluene } \\
\text { o-Xylene }\end{array}$ & $\begin{array}{l}\text { Ethanol/Methanol/ } \\
\text { Water }\end{array}$ \\
Pressure $(P)$ & $101.325 \mathrm{kPa}$ & $101.325 \mathrm{kPa}$ & $101.325 \mathrm{kPa}$ & $101.325 \mathrm{kPa}$ \\
\hline Fumber of trays $(N T)$ & 14 & 21 & 14 & 15 \\
\hline Feed location $(N F)$ & 7 & 11 & 7 & 12 \\
\hline $\begin{array}{l}\text { Feed flow }\left(M_{F}^{N F}\right) \\
x_{1}^{F}\end{array}$ & $375 \mathrm{~mol} / \mathrm{cycle}$ & $833.33 \mathrm{~mol} / \mathrm{cycle}$ & $375 \mathrm{~mol} / \mathrm{cycle}$ & $200 \mathrm{~mol} / \mathrm{cycle}$ \\
$x_{2}^{F}$ & $50 \mathrm{~mol} \%$ & $50 \mathrm{~mol} \%$ & $45 \mathrm{~mol} \%$ & $15 \mathrm{~mol} \%$ \\
\hline$x_{3}^{F}$ & $50 \mathrm{~mol} \%$ & $50 \mathrm{~mol} \%$ & $45 \mathrm{~mol} \%$ & $5 \mathrm{~mol} \%$ \\
\hline Constant vapour flow $(V)$ & $36.83 \mathrm{~mol} / \mathrm{s}$ & $42.78 \mathrm{~mol} / \mathrm{s}$ & $29.17 \mathrm{~mol} / \mathrm{s}$ & $5 \mathrm{~mol} / \mathrm{s}$ \\
\hline VFP duration $\left(t_{V F P}\right)$ & $12 \mathrm{~s}$ & $25 \mathrm{~s}$ & $12 \mathrm{~s}$ & $25 \mathrm{~s}$ \\
\hline LFP duration $\left(t_{L F P}\right)$ & $3 \mathrm{~s}$ & $5 \mathrm{~s}$ & $3 \mathrm{~s}$ & $5 \mathrm{~s}$ \\
\hline Distillate $(D)$ & $187.5 \mathrm{~mol} / \mathrm{cycle}$ & $416.665 \mathrm{~mol} / \mathrm{cycle}$ & $187.5 \mathrm{~mol} / \mathrm{cycle}$ & $25 \mathrm{~mol} / \mathrm{cycle}$ \\
\hline Boilup ratio $(B R)$ & 0.09 & 0.12 & 0.08 & 0.07 \\
\hline Condenser holdup $\left(M_{1}^{0}\right)$ & $5 \mathrm{kmol}$ & $10 \mathrm{kmol}$ & $5 \mathrm{kmol}$ & $2 \mathrm{kmol}$ \\
\hline Reboiler holdup $\left(M_{N T}^{0}\right)$ & $5 \mathrm{kmol}$ & $10 \mathrm{kmol}$ & $5 \mathrm{kmol}$ & $2 \mathrm{kmol}$ \\
\hline
\end{tabular}

This article is protected by copyright. All rights reserved. 
TAB LE 6 Relative changes in composition of EtOH in condenser from quasi-stationary steady-state for changes in feed composition for the ethanol/methanol/water case.

\begin{tabular}{|lcc|}
\hline Change in feed EtOH & Simple model & Extended model \\
\hline$+5 \%$ & $0.64 \%$ & $0.62 \%$ \\
\hline$-5 \%$ & $-0.69 \%$ & $-0.67 \%$ \\
\hline
\end{tabular}

TABLE 7

\begin{tabular}{|c|c|c|c|}
\hline \multicolumn{4}{|c|}{ Nomenclature } \\
\hline$B$ & bottoms (mol/cycle) & Greek & \\
\hline$B R$ & boilup ratio & $\gamma$ & activity coefficient \\
\hline$C_{P}$ & specific heat capacity $(\mathrm{J} /(\mathrm{K}$ mol$))$ & Subscripts & \\
\hline$D$ & distillate (mol/cycle) & $i$ & component ID \\
\hline$h$ & liquid enthalpy $(J)$ & $n$ & stage number \\
\hline$H$ & vapour enthalpy (J/mol) & Superscripts & \\
\hline$\Delta H_{v a p}^{\circ}$ & standard heat of vaporisation $(\mathrm{J} / \mathrm{mol})$ & $F$ & feed \\
\hline K & equilibrium constant & $L$ & liquid phase \\
\hline L & reflux (mol/cycle) & $(L F P)$ & end of LFP \\
\hline$M$ & molar holdup (mol) & $S D$ & side draw \\
\hline$N$ & number of cycles & V & vapour phase \\
\hline NC & number of components & (VFP) & end of VFP \\
\hline$N T$ & number of trays & 0 & initial condition \\
\hline$P$ & stage pressure $(\mathrm{Pa})$ & & \\
\hline$P^{s a t}$ & saturation pressure $(\mathrm{Pa})$ & & \\
\hline$Q$ & energy $(\mathrm{J} / \mathrm{s})$ & & \\
\hline$S$ & side draw (mol/cycle) & & \\
\hline$t$ & time (s) & & \\
\hline$t_{L F P}$ & duration of LFP (s) & & \\
\hline$t_{V F P}$ & duration of VFP (s) & & \\
\hline$T$ & temperature $(\mathrm{K})$ & & \\
\hline$T_{b, i}$ & pure component boiling point (K) & & \\
\hline$V$ & vapour flow rate (mol/s) & & \\
\hline$x$ & liquid composition (mol/mol) & & \\
\hline$y$ & vapour composition (mol/mol) & & \\
\hline
\end{tabular}

This article is protected by copyright. All rights reserved. 